\title{
Effects of water restriction and water loading on daily urinary excretion of heavy metals and organic substances in metal workers
}

\author{
S ARAKI,' H AONO ${ }^{2}$ \\ From the Department of Public Health, ${ }^{1}$ School of Medicine, University of Tokyo, Hongo, Bunkyo-ku, Tokyo \\ 113, and the Department of Public Health and Hygiene, ${ }^{2}$ Medical College of Oita, Hazama-machi, Oita 879-56, \\ Japan
}

ABSTRACT The effects of urinary volume on daily urinary excretion of seven heavy metals and four organic substances were examined in relation to the changes in their plasma and erythrocyte concentrations and urinary creatinine excretion in 19 metal workers. The examination was conducted under the conditions of water restriction and loading for six days. The major findings were as follows: (1) urinary excretion of all heavy metals and organic substances except mercury, together with creatinine excretion, significantly decreased under the water restrictive condition whereas under the water loading condition their excretion significantly increased and (2) daily variations in urinary excretion of lead, cadmium, chromium, copper, hippuric acid, $\delta$-aminolaevulinic acid, and coproporphyrin did not differ significantly from the variation in urinary excretion of creatinine (profile analysis, $\mathrm{p}>\mathbf{0 . 0 5}$ ). It is suggested that glomerular filtration is the major factor determining renal excretory mechanisms of the four heavy metals and three organic substances examined.

We have found that the urinary excretion of various heavy metals and organic substances is significantly affected by urinary volume (UV) in metal workers ${ }^{\prime}$ and in healthy controls. ${ }^{2}$ These findings were consistent with previous observations ${ }^{34}$ that 24 hour urinary excretion of lead $(\mathrm{Pb})$ and $\delta$-aminolaevulinic acid (ALA) significantly decreased when UV was reduced. The findings, ${ }^{12}$ however, contrasted sharply with previous observations ${ }^{34}$ that the excretion of coproporphyrin (CP) and creatinine ( $\mathrm{Cn}$ ) was independent of UV.

To examine the effects of UV on 24 hour urinary excretion of substances further, we have measured the excretions of various heavy metals and organic substances in the urine under the conditions of water restriction and water loading. In addition, daily variations in urinary excretion of substances were compared with the variations in UV, urinary $\mathrm{Cn}$ excretion, and plasma and erythrocyte concentrations of those substances using profile analysis. ${ }^{5}$

\section{Subjects and methods}

\section{SUBJECTS}

The 19 subjects (workers exposed to $\mathrm{Pb}$, zinc $(\mathrm{Zn})$,

Accepted 13 June 1988 copper $(\mathrm{Cu})$, and tin) were male metal foundry workers aged 34 to 59 . Their blood $\mathrm{Pb}$ concentrations ranged from 25 to $59 \mu \mathrm{g} / \mathrm{dl}$ (mean $39 \mu \mathrm{g} / \mathrm{dl}(1.9$ $\mu \mathrm{mol} / \mathrm{l})$ ). No subject had ever suffered from renal disease; nor were albuminuria or glucosuria found in any subject.

\section{COLLECTION OF BLOOD AND URINE SAMPLES}

The procedure was explained to all subjects and this study was conducted with their informed consent. After maintaining their usual intake of food and liquid for two days (free condition), the subjects drank less than 0.251 of liquid a day for another two days (water restrictive condition) and were then loaded with more than 31 of water for two successive days (water loading condition). Twenty four hour urine samples (0700-0700) were collected on all workers every day for six days; venous blood samples were collected at 1000 daily for six days. All subjects were admitted to a special room for health examination at the Medical College of Oita during the six day period, and they ate all meals in the hospital dining room. To minimise the intake of organic mercury, they consumed little fish and shellfish.

ANALYTICAL METHODS

Analytical methods, lower limits of detection, and 
reproducibility of analysis for all substances examined in the present study have been reported previously. ${ }^{16}$ Blood, erythrocyte, and urinary $\mathrm{Pb}$ concentrations were measured by atomic absorption spectrophotometry (AAS) after wet ashing, chelation by sodium diethyl dithiocarbamate (DDTC), and extraction to water saturated methyl isobutyl ketone (MIBK); the plasma $\mathrm{Pb}$ concentration was measured by the method of de Silva. ' Plasma, erythrocyte, and urinary concentrations of total (inorganic and organic) mercury $(\mathrm{Hg})$ were determined by the method of Magos. ${ }^{89}$ Plasma and erythrocyte concentrations of cadmium $(\mathrm{Cd})$ and $\mathrm{Cu}$ were measured by the flameless AAS after deproteinisation by trichloroacetic acid (TCA) and urinary Cd by the method of Subramanian et al. ${ }^{10}$ Plasma and erythrocyte concentrations of manganese (Mn) and chromium $(\mathrm{Cr})$ were measured by the flameless AAS using the standard addition technique after deproteinisation by TCA; urinary Mn, $\mathrm{Cr}$, and $\mathrm{Cu}$ concentrations by the AAS after wet ashing, chelation by DDTC, and extraction to MIBK. Plasma and urinary $\mathrm{Zn}$ concentrations were measured by the AAS after deproteinisation by TCA; erythrocyte $\mathrm{Zn}$ by the AAS after wet ashing. Plasma and urinary $\beta$-2-microglobulin (BMG) concentrations were measured by the radioimmunoassay method; urinary hippuric acid (HA), ALA, and CP by the
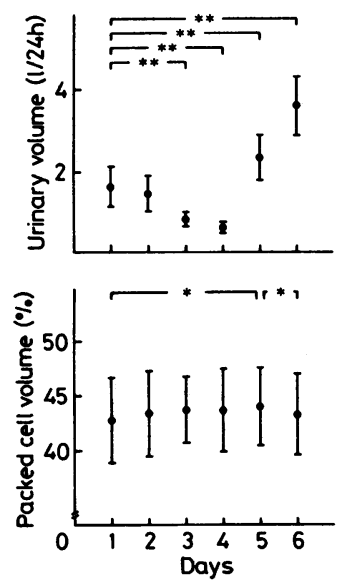

Fig 1 Daily variations in urinary volume, urinary creatinine (UCn), and packed red blood cell volume for six days in 19 metal workers (mean $\pm S D$ ). Days 1 and 2 represent free condition, 3 and 4 show water restrictive condition, and 5 and 6 are water loading condition. Packed red blood cell volume was measured at 1000 on all six days. * and ** indicate significant differences between two days at levels of $p<0.05$ and 0.01 , respectively. Urinary volume and UCn on day 2 also differed significantly from those on days 3 to 6 $(p<0.01)$. (1 g/24h for UCn corresponds to $8.8 \mathrm{mmol} / 24 \mathrm{~h}$.) benzenesulphonyl chloride method, the methods of $\bar{Z}$

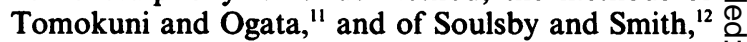
respectively; urinary $\mathrm{Cn}$ by Jaffe's reaction; and urinary specific gravity (SG) by refractometry. The $\stackrel{\bar{S}}{\stackrel{5}{9}}$ urinary concentration of total urinary solutes (TUS) was calculated from urinary SG and Haeser's index.

\section{STATISTICAL ANALYSIS}

Differences in daily urinary excretion and plasma and erythrocyte concentrations of substances were tested by the paired sample $t$ test. Parallelisms of daily? urinary excretion of substances to daily urinary $\overrightarrow{\vec{\omega}}$ volume, $\mathrm{Cn}$ excretion, and plasma and erythrocyte $\mathrm{o}$

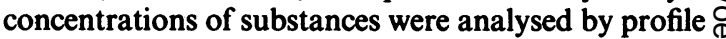
analysis using the $\mathrm{F}$ test. $^{5}$
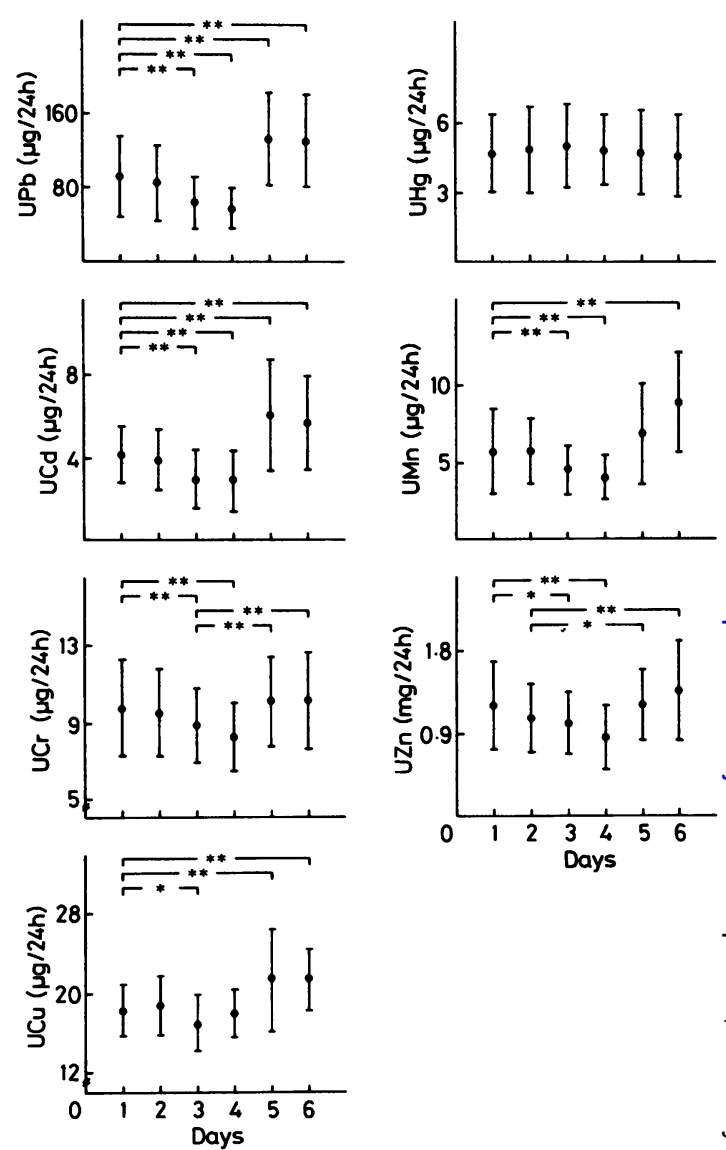

Fig 2 Daily variations in urinary lead (UPb), mercury (UHg), cadmium (UCd), manganese (UMn), chromium $(U C r)$, zinc $(U Z n)$, and copper (UCu) for six days in 19 metal workers. Examination days, vertical lines, and signs as in fig 1 . ( $1 \mu \mathrm{g} / 24 \mathrm{~h}$ for $U \mathrm{~Pb}, U \mathrm{Hg}, U C d, U M n, U C r, U Z n$, and $U C u$ correspond to $4 \cdot 8,5 \cdot 0,8 \cdot 9,18,19,15$, and 16 $n$ mol/24 $h$, respectively.) 

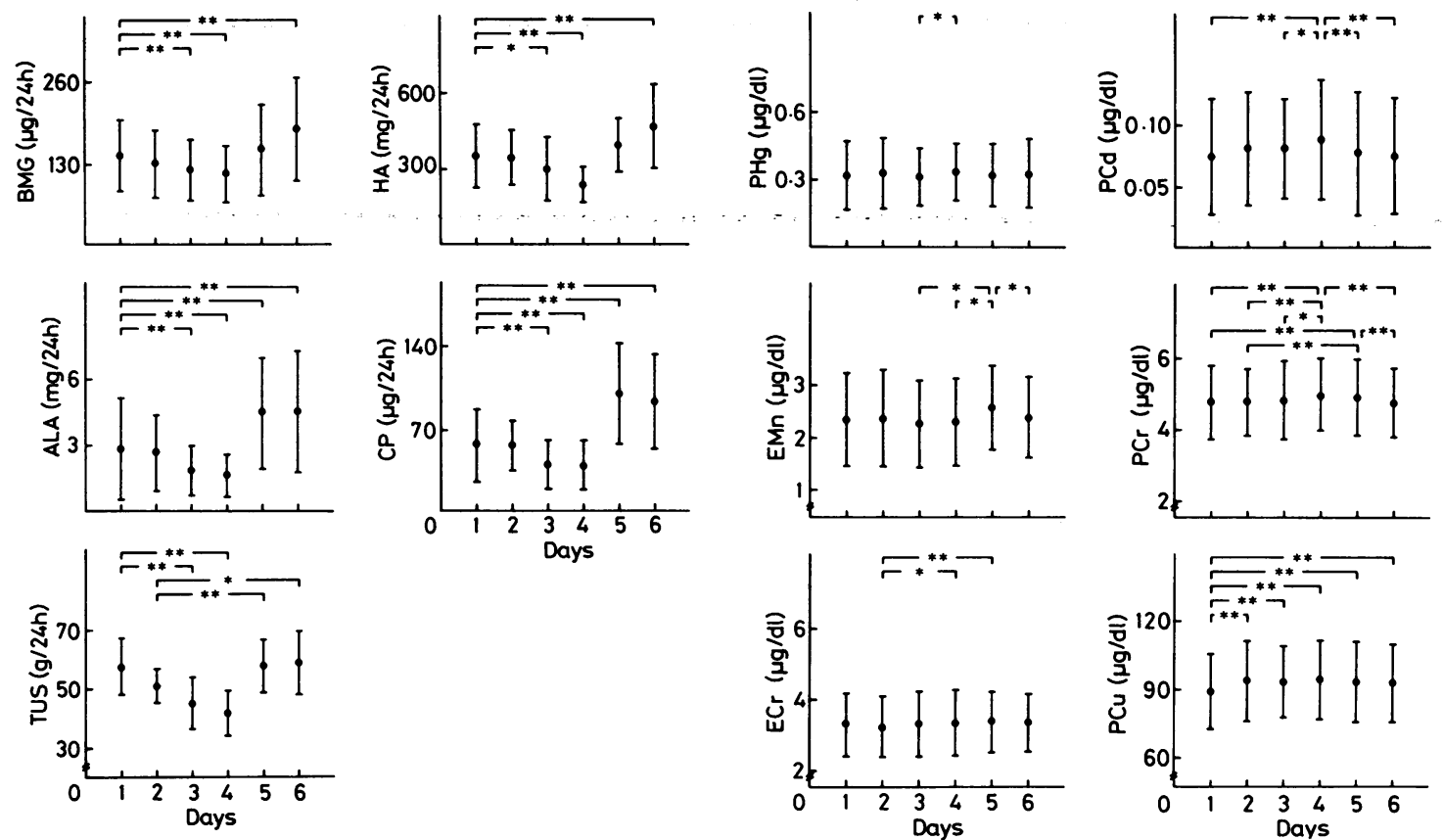

Fig 3 Daily variations in urinary $\beta$-2-microglobulin $(B M G)$, hippuric acid $(H A), \delta$-aminolaevulinic acid $(A L A)$, coproporphyrin (CP), and total solutes (TUS) for six days in 19 metal workers. Examination days, vertical lines, and signs as in fig $1 .(1 \mathrm{mg} / 24 \mathrm{~h}$ for $B M G, H A, A L A$, and $C P$ correspond to $0 \cdot 085,5 \cdot 6,7 \cdot 6$, and $1.5 \mu \mathrm{mol} / 24 \mathrm{~h}$, respectively.)

Fig 4 Daily variations in mercury, cadmium, chromium, and copper in plasma ( $\mathrm{PHg}, \mathrm{PCd}, \mathrm{PCr}$, and $\mathrm{PCu})$ and manganese and chromium in erythrocytes (EMn and ECr) for six days in 19 metal workers. Examination days, vertical lines, and signs as in fig $1.1 \mu \mathrm{g} / \mathrm{dl} \mathrm{for} \mathrm{PHg}, \mathrm{PCd}, \mathrm{EMn}, \mathrm{PCr}$, ECr, and PCu correspond to 0.050, 0.089, 0.18, 0.19, 0.19, and $0 \cdot 16 \mu \mathrm{mol} / \mathrm{l}$, respectively.

\section{Results}

The daily urinary excretion of each heavy metal and organic substance except $\mathrm{Hg}$, and $\mathrm{UV}, \mathrm{Cn}$, and TUS, significantly decreased under the water restrictive

condition, and significantly increased under the water loading condition (figs 1-3). The concentrations of $\mathrm{Hg}, \mathrm{Cd}, \mathrm{Cr}$, and $\mathrm{Cu}$ in plasma, the concentrations of $\mathrm{Mn}$ and $\mathrm{Cr}$ in erythrocytes, and packed red blood cell volume were significantly higher in the fourth or fifth

Parallelisms of daily urinary excretion of heavy metals, organic substances, total solutes, and creatinine to daily urinary volume and creatinine excretion, and to plasma and erythrocyte concentrations of each substance for six days in 19 metal workers under conditions of water restriction and loading: profile analysis ( $F$ values)

\begin{tabular}{|c|c|c|c|c|}
\hline & $\begin{array}{l}\text { Urinary } \\
\text { volume }\end{array}$ & $\begin{array}{l}\text { Urinary } \\
\text { creatinine }\end{array}$ & $\begin{array}{l}\text { Plasma } \\
\text { concentration of } \\
\text { each substance }\end{array}$ & $\begin{array}{l}\text { Erythrocyte } \\
\text { concentration of } \\
\text { each metal }\end{array}$ \\
\hline $\begin{array}{l}\text { Lead } \\
\text { Mercury } \\
\text { Cadmium } \\
\text { Manganese } \\
\text { Chromium } \\
\text { Zinc } \\
\text { Copper } \\
\beta \text {-2-microglobulin } \\
\text { Hippuric acid } \\
\delta \text {-Aminolaevulinic acid } \\
\text { Coproporphyrin } \\
\text { Total solutes } \\
\text { Creatinine }\end{array}$ & $\begin{array}{l}8 \cdot 266^{* *} \\
8 \cdot 844^{* *} \\
4.230^{* *} \\
4.889^{* *} \\
7 \cdot 320^{* *} \\
5.245^{* *} \\
6.902^{* *} \\
3.526^{*} \\
2.968^{*} \\
6.415^{* *} \\
11.613^{* *} \\
9.062^{* *} \\
4.964^{* *}\end{array}$ & $\begin{array}{l}1 \cdot 163 \\
5.516^{* *} \\
1.028 \\
4.692^{* *} \\
1.653 \\
4.955^{* *} \\
2.008 \\
3.666^{* *} \\
1.376 \\
1.243 \\
1.258 \\
6.903^{* *}\end{array}$ & $\begin{array}{l}14 \cdot 471^{* *} \\
2 \cdot 605^{*} \\
25 \cdot 544^{* *} \\
18 \cdot 579^{* *} \\
14 \cdot 194^{* *} \\
2 \cdot 915^{*} \\
13 \cdot 591^{* *} \\
11 \cdot 910^{* *} \\
= \\
= \\
- \\
-\end{array}$ & $\begin{array}{l}10 \cdot 307^{* *} \\
0 \cdot 488 \\
20 \cdot 852^{* *} \\
11 \cdot 507^{* *} \\
4 \cdot 542^{* *} \\
1 \cdot 885 \\
14 \cdot 970^{* *} \\
= \\
= \\
= \\
-\end{array}$ \\
\hline
\end{tabular}

*p $<0.05 ;{ }^{* *}$ p $<0.01$

-Plasma and erythrocyte concentrations were not measured. 
examination days, or both (figs 1 and 4).

The results of profile analysis indicated that daily variations in urinary excretion of $\mathrm{Pb}, \mathrm{Cd}, \mathrm{Cr}, \mathrm{Cu}, \mathrm{HA}$, ALA, and CP did not significantly differ from the variation in urinary $\mathrm{Cn}$ excretion (table). On the other hand, daily variations in all urinary heavy metals and organic substances, together with urinary $\mathrm{Cn}$ and TUS, differed significantly from the variation in UV; the variations in all urinary heavy metals and BMG differed significantly from the variations in the plasma concentrations of the metals and BMG; and the variations in all urinary heavy metals except $\mathrm{Hg}$ and $\mathrm{Zn}$ differed significantly from the variations in the erythrocyte concentrations of the metals (table).

\section{Discussion}

Pronounced effects of UV on the daily urinary excretion of all the heavy metals and organic substances except $\mathrm{Hg}$ were found; daily excretion of these substances under the water loading condition was nearly twice as large as the excretion under the water restrictive condition (figs 2 and 3 ). Thus it is essential to take into account the effects of UV in the biological monitoring of these heavy metals and organic substances.

Packed red blood cell volume and the plasma or erythrocyte concentration, or both, of six heavy metals reached the highest levels in the fourth or fifth days of examination-that is, in the later stage of water restriction. This was probably due to dehydration under the water restrictive condition.

The daily variations in urinary excretion of $\mathrm{Pb}, \mathrm{Cd}$, $\mathrm{Cr}$, and $\mathrm{Cu}$ were closely associated with the variation in urinary $\mathrm{Cn}$ excretion but not with the variations in the plasma and erythrocyte concentrations of each metal nor with the variation in UV (table, figs 1,2 ). Evidence has been given that in man: (1) glomerular filtration rate (GFR) (inulin or endogenous creatinine clearance) is greatly altered under the conditions of water restriction and loading ${ }^{13}$; (2) substantial amounts of heavy metals are filtered at the glomerulus. ${ }^{14}$ These data indicate that a change in GFR is the major factor determining the variations in urinary excretion of those metals under the conditions of water restriction and loading. The same mechanism may also be responsible for the variations in urinary excretion of many organic substances.

Daily variations in urinary excretion of $\mathrm{Mn}, \mathrm{Zn}$, and BMG, on the other hand, were significantly associated neither with the variations in urinary $\mathrm{Cn}$ excretion nor with the plasma concentrations. Mn, $\mathrm{Zn}$, and BMG have been found to be also filtered at the glomerulus in man. ${ }^{14} 15$ Therefore, the present observation may reflect the complex renal excretory mechanisms of those substances.

Finally, urinary excretion of $\mathrm{Hg}$ was independent of the variations in UV and in urinary excretion of $\mathrm{Cn}_{\bar{Z}}$ The latter observation suggests that $\mathrm{Hg}$ is not filtered at the glomerulus; most studies by us ${ }^{141617}$ and by: others ${ }^{18}$ are in line with this finding. It appears that $\mathrm{H} / \overline{\mathrm{g}}$ is the only metal that has been found to have such of characteristic renal excretory mechanism.

\section{References}

1 Araki S, Aono H, Murata K. Adjustment of urinary concentrations to urinary volume in relation to erythrocyte and plasma concentrations: an evaluation of urinary heavy metals and organic substances. Arch Environ Health 1986;41:171-7.

2 Araki S, Murata K, Aono H, et al. Comparison of the effects of urinary flow on adjusted and non-adjusted excretion of heavyD metals and organic substances in "healthy" men. J Appl Toxico $\$$ 1986;6:245-51.

3 Araki S. The effects of water restriction and water loading or urinary excretion of lead, $\delta$-aminolaevulinic acid, and coproporphyrin. Br J Ind Med 1978;35:312-7.

4 Araki $S$. Effects of urinary volume on urinary concentrations of lead, $\delta$-aminolaevulinic acid, coproporphyrin, creatinine, ans total solutes. Br J Ind Med 1980;37:50-4.

5 Morrison DF. Multivariate statistical methods. 2nd ed. New Yorke McGraw-Hill, 1976:153-60.

6 Araki S, Aono H, Murata K. Mobilisation of heavy metals into theD urine by CaEDTA: relation to erythrocyte and plasma concen trations and exposure indicators. Br J Ind Med 1986;43:636-41.

7 de Silva PE. Determination of lead in plasma and studies on it relationship to lead in erythrocytes. Br J Ind Med 1981;38 209-17.

8 Magos L. Selective atomic-absorption determination of inorganic mercury and methylmercury in undigested biological samples $\bar{\partial}$ Analyst 1971;96:847-53.

9 Magos L, Clarkson TW. Atomic absorption determination of total, inorganic, and organic mercury in blood. J Assoc Off AnaP Chem 1972;55:966-71.

10 Subramanian KS, Meranger J-C, MacKeen JE. Graphite furnace atomic absorption spectrometry with matrix modification for determination of cadmium and lead in human urine. Anal Chem 1983;55:1064-7.

11 Tomokuni K, Ogata M. Simple method for determination ôิ urinary $\delta$-aminolevulinic acid as an index of lead exposure. Clin Chem 1972;18:1534-6.

12 Soulsby J, Smith RL. A simplified method for the quantitative determination of urinary coproporphyrin in lead workers. $\mathrm{Br} P$. Ind Med 1974;31:72-4.

13 Wesson LG. Physiology of the kidney. In: Alken CE, Dix VW, Weyrauch HM, Wildbolz E, eds. Encyclopedia of urology. VoK II. Physiology and pathological physiology. Berlin: Springer-윽 Verlag, 1965:1-386.

14 Araki S, Aono H, Yokoyama K, Murata K. Filterable plasmao concentration, glomerular filtration, tubular balance, and renal三 clearance of heavy metals and organic substances in metaln workers. Arch Environ Health 1986;41:216-21.

15 Buchet JP, Roels H, Bernard A, Lauwerys R. Assessment of renalN function of workers exposed to inorganic lead, cadmium orn mercury vapor. J Occup Med 1980;22:741-50.

16 Araki S, Murata K, Yokoyama K, et al. Circadian rhythms in the urinary excretion of metals and organic substances in "healthy" men. Arch Environ Health 1983;38:360-6.

17 Yokoyama K, Araki S, Yamamoto R. Renal handling of "filterable" plasma metals and organic substances in man. $f$ : Appl Toxicol 1985;5:94-6.

18 Cherian MG, Hursh JB, Clarkson TW, Allen J. Radioactive mercury distribution in biological fluids and excretion in human $\mathbb{D}$

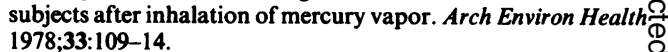

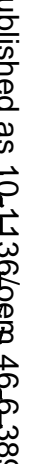

